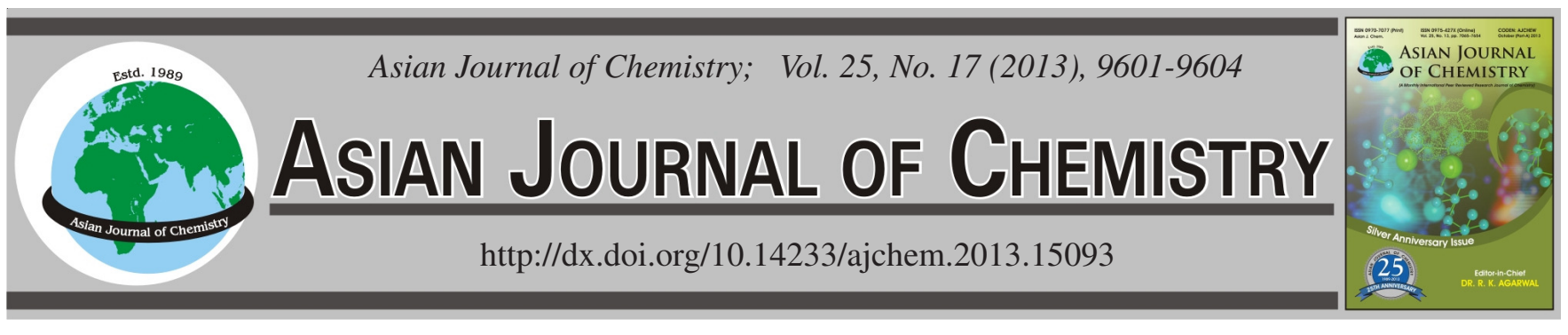

\title{
Optical Properties of Indium-Doped ZnO Nano-Films Prepared by Spray Pyrolysis and Hydrothermal Synthesis
}

\author{
RuXi Liu, Zhong Zhang ${ }^{*}$, JinZhao Huang and Honglin Li
}

School of Physics Science, University of Jinan, Jinan 250022, Shandong Province, P.R. China

*Corresponding author: Tel: +86 15168808080; E-mail: ss_zhangz@ujn.edu.cn

(Received: 4 January 2013;

Accepted: 7 October 2013)

AJC-14236

Zinc oxide and indium-doped $\mathrm{ZnO}$ nano-films are prepared by two-step method on the quartz glass substrate. The growth orientation
along c-axis of $\mathrm{ZnO}$ nano rods is changed by indium doping and with the increase of indium proportion, the orientation along (101) plane
increase. The structure changes from prism-like nano rods to nanofilms due to the different indium proportion. New energy levels are
introduce into $\mathrm{ZnO}$ causing a blue shift in the green emission region and more oxygen vacancies that results a better blue emission at $404 \mathrm{~nm}$.
Key Words: Zinc oxide, Spray pyrolysis Method, Hydrothermal synthesis method, Indium doping, Nano structure.

\section{INTRODUCTION}

Zinc oxide is a research hotspot of the 3rd generation semicondutor with a wide bandgap energy $(3.37 \mathrm{eV})$ and a large excitation binding energy $(60 \mathrm{meV})$ at room temperature. Nanoscale $\mathrm{ZnO}$ structures are different from bulk materials due to quantum scale effect as the result of that their increased surface area and they show their favourable structural, optical and catalytic properties. Zinc oxide nano structures are often used as light-emission diode ${ }^{1}$, gas sensors ${ }^{2}$, antireflective coating $^{3}$, photocatalyst $^{4}$ and in solar cells ${ }^{5}$.

The synthesis of $\mathrm{ZnO}$ nano structure have been carried out using chemical methods such as sol-gel method ${ }^{6}$, metalorganic chemical vapor deposition (MOCVD) ${ }^{7}$, thermal evaporation deposition ${ }^{8}$, electrochemical deposition ${ }^{9}$, hydrothermal $\operatorname{method}^{10}$, magnetron sputtering method ${ }^{11}$ and anodic alumina templates etc. ${ }^{12}$ and physical methods as pulsed laser deposition $(\mathrm{PLD})^{13}$ and molecular beam epitaxy (MBE), etc. ${ }^{14}$.

The undoped $\mathrm{ZnO}$ films are not very stable especially at high temperatures, but the doped $\mathrm{ZnO}$ films can reduce the disadvantage and increase the conductivity. Though doping can improve the quality of $\mathrm{ZnO}$ films, the efficiency of the dopant element depends on its electronegativity and difference between its ionic radius and the ionic radius of $z_{\text {inc }}{ }^{15}$. Most indium doped $\mathrm{ZnO}$ films are prepared by spray pyrolysis ${ }^{2,15}$. In this paper, the $\mathrm{ZnO}$ and indium-doped $\mathrm{ZnO}$ nano-films are prepared by two-step method using different indium concentrations at $[\mathrm{In}] /[\mathrm{Zn}]=3,5,8,10$ at $\%$. The $\mathrm{ZnO}$ seeds layer is prepared on the substrates by spray pyrolysis firstly and then the indium-doped $\mathrm{ZnO}$ nano-films are prepared by hydrothermal synthesis.

\section{EXPERIMENTAL}

Materials used in the experiment were quartz glass, zinc acetate, ammonia, indium chloride, zinc nitrate hexahydrate and hexamethlylenetetramine. The methods employed for indium doped $\mathrm{ZnO}$ nano films were spray pyrolysis and hydrothermal synthesis.

General procedure: The seeds layer is prepared by spray pyrolysis on the quartz glass at $300^{\circ} \mathrm{C}$ with $0.5 \mathrm{M}$ zinc acetate. The $\mathrm{ZnO}$ growth solution is prepared by dropping ammonia to the solution of zinc nitrate hexahydrate and hexamethlylenetetramine till it turns to transparent. Then the substrate is put into the solution vertically in the autoclave. The final growth is carried out at $100{ }^{\circ} \mathrm{C}$ and the time of $2 \mathrm{~h}$. By dissolving different weight indium chloride also to the solution of zinc nitrate hexahydrate and hexamethlylenetetramine and repeating final growth process as $\mathrm{ZnO}$ nano-films, the indium-doped $\mathrm{ZnO}$ nano-films are prepared. All the samples prepared are annealed at $300^{\circ} \mathrm{C}$ to $0.5 \mathrm{~h}$, then quenched to the room temperature and finally cleaned by ethanol and deionized water before tested.

Detection method: The as-grown films are tested by the X-ray diffraction (XRD), the scanning electron microscopy (SEM), the photoluminescence (PL) and current-voltage characteristics curves (I-V) to indicate the influence of indiumdoping to $\mathrm{ZnO}$ nano-films.

\section{RESULTS AND DISCUSSION}

Fig. 1 shows the XRD patterns of $\mathrm{ZnO}$ and indium-doped $\mathrm{ZnO}$ nano-films. All the diffraction peaks in each patterns consistent with the standard card (JCPDS card 36-1451), which 


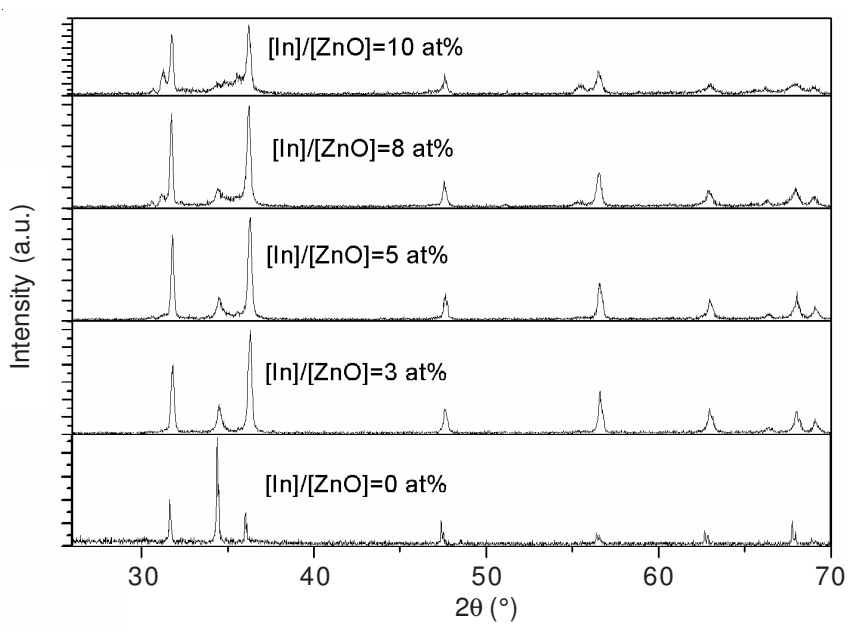

Fig. 1. XRD patterns of $\mathrm{ZnO}$ and indium-doped $\mathrm{ZnO}$ nano-films

represents the wurtzite structure of $\mathrm{ZnO}$. Compared to none indium-doped $\mathrm{ZnO}$ nano-films, the c-axis orientation along the (002) plane decrease with the increase of indium proportion and the peak of orientation along (101) plane increase, when the indium proportion up to $10 \%$, the diffraction peak of (002) plane almost disappears, all above indicate that the growth orientation of the $\mathrm{ZnO}$ crystal is obviously influenced by the incorporation of indium. The ionic radius of indium is more than the zinc ionic radius, so that the lattice expands and the lattice parameters increase when indium ionic replaces $\mathrm{Zn}$ ionic in the $\mathrm{ZnO}$ lattice, resulting a shift to the small angle direction of the diffraction peaks of (100), (002) and (101) plane of indium-doped $\mathrm{ZnO}$ nano-films compared to the standard card and the change of the distance of the two crystal plane is $3.5 \times$ $10^{-3} \mathrm{~nm}$. Diffraction peaks of the patterns from $\mathrm{ZnO}$ to indiumdoped $\mathrm{ZnO}$ at $10 \%$ nano-films become wider, indicating a lower crystallinity and smaller average grain size which can be corroborated by Scherer Formula (the calculated average grain sizes are 2.144976, 1.244333, 1.190992, 1.052201 and $1.211128 \mathrm{~nm}$, respectively). The pattern of $8 \%$ indium proportion shows a new peak on the left of the (100) plane peak indicating the diffraction peak of $\operatorname{In}_{2} \mathrm{O}_{3}$ and it is stronger in the pattern of the $10 \%$ indium proportion. The peak of $\mathrm{In}_{2} \mathrm{O}_{3}$ indicates that not all $\mathrm{Zn}$ ionics are replaced by indium ionics, but some indium ionics form $\operatorname{In}_{2} \mathrm{O}_{3}$ in the wurtzite structure of $\mathrm{ZnO}$.

Fig. 2 are the SEM images showing the morphology of indium-doped $\mathrm{ZnO}$ nano-films. Fig. 2(a) shows the wurtzite structure of $\mathrm{ZnO}$ nanorods that is prism-like. Most nanorods grow vertically from the substrate mostly and few grow along the horizontal direction. The bottom of the rods is thinner than the upper indicating that the rod structure is grown from the seed layers and the preferential growth direction of the seed layers decides the growth direction of the rods, so that the nanorods grow along different direction. Fig. 2(b) is the flowerlike nano structure image of indium proportion at $3 \%$. The flower-like structure is the result of the distorted rod-like structure and there are fluffs formed on the surface of the rods and the rod structure becomes being deform caused by the indium doping, the complete rod structure in the upper left corner indicates that small amount indium ionic are doped into the $\mathrm{ZnO}$ structure. Fig. 2(c-e) are the images of different indium
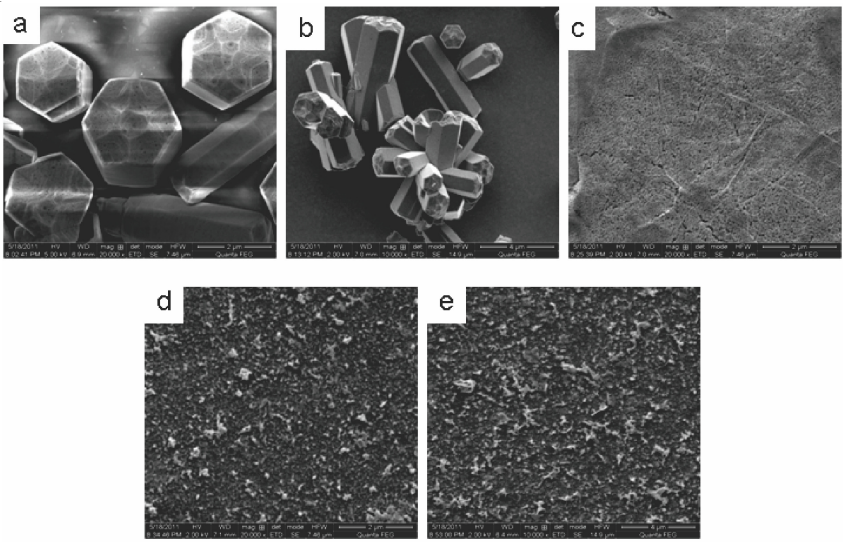

Fig. 2. SEM images of $\mathrm{ZnO}$ and indium-doped $\mathrm{ZnO}$ nano-films. (a) prismlike nano rod structure of $\mathrm{ZnO}$, (b) flower-like stucture of $\mathrm{ZnO}$ at $3 \%$ of indium proportion, (c) nano-films of $\mathrm{ZnO}$ at $5 \%$ of indium proportion, (d) nano-films of $\mathrm{ZnO}$ at $8 \%$ of indium proportion and (e) nano-films of $\mathrm{ZnO}$ at $10 \%$ of indium proportion

doping proportion $\mathrm{ZnO}$ nano-films at 5, 8 and $10 \%$, respectively. The surface of the nano-films becomes irregular with the increase of indium proportion and the growth direction changes instead of along the c-axis mainly indicating that the wurtzite structure of $\mathrm{ZnO}$ deforms due to the doping of indium in the growth progress. The SEM images consistent to the XRD patterns that the growth orientation changes remarkably.

Fig. 3 shows the photoluminescence emission spectra of the samples. The photoluminescence peaks are attributed by a $325 \mathrm{~nm}$ excitation from LS55 fluorescence spectrophotometer of Perkin Elmer company. After indium doping, the visible luminescence intensity of nano-films became higher and entirely intensity became lower than $\mathrm{ZnO}$ nano-structure, this depends on sample type and excitation intensity ${ }^{16}$.

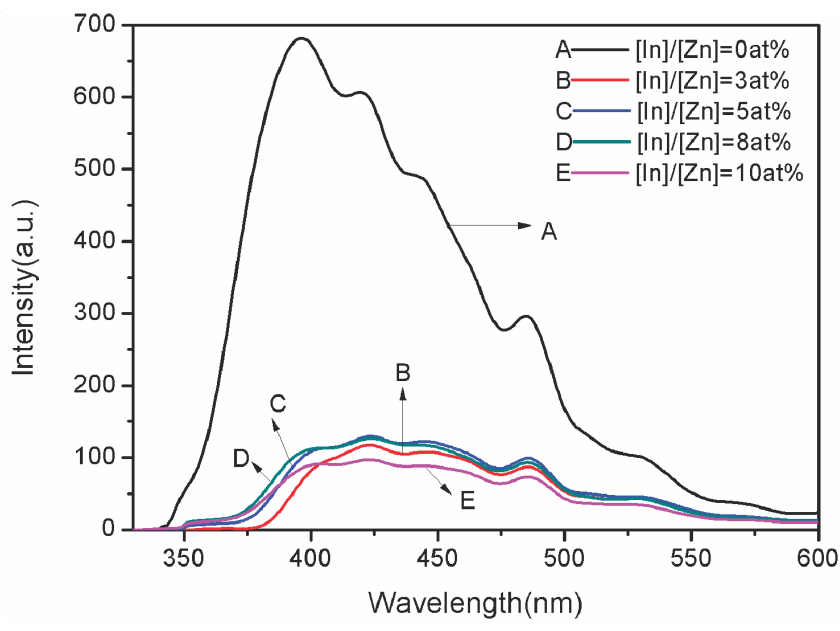

Fig. 3. Photoluminescence sectra of $\mathrm{ZnO}$ and indium-doped $\mathrm{ZnO}$ nano-films

The photoluminescence spectra are Gaussian deconvoluted to the sub peaks according to their origination to investigate deep of the photoluminescence spectra, showed as Fig. 4.

The UV emission at $388 \mathrm{~nm}$ is assigned to a shallow donor of the complex defect of $\mathrm{Zn}_{\mathrm{i}}{ }^{17}$ and also the peak at $421 \mathrm{~nm}^{18}$. The peaks at 489 and $520 \mathrm{~nm}$ are mostly attriburted to $\mathrm{V}_{\mathrm{O}}{ }^{19}$ and $\mathrm{O}_{\mathrm{Zn}}{ }^{20}$, respectively. The peaks that are bigger than $540 \mathrm{~nm}$ are ascribed to $\mathrm{O}_{\mathrm{i}}^{21}$. 

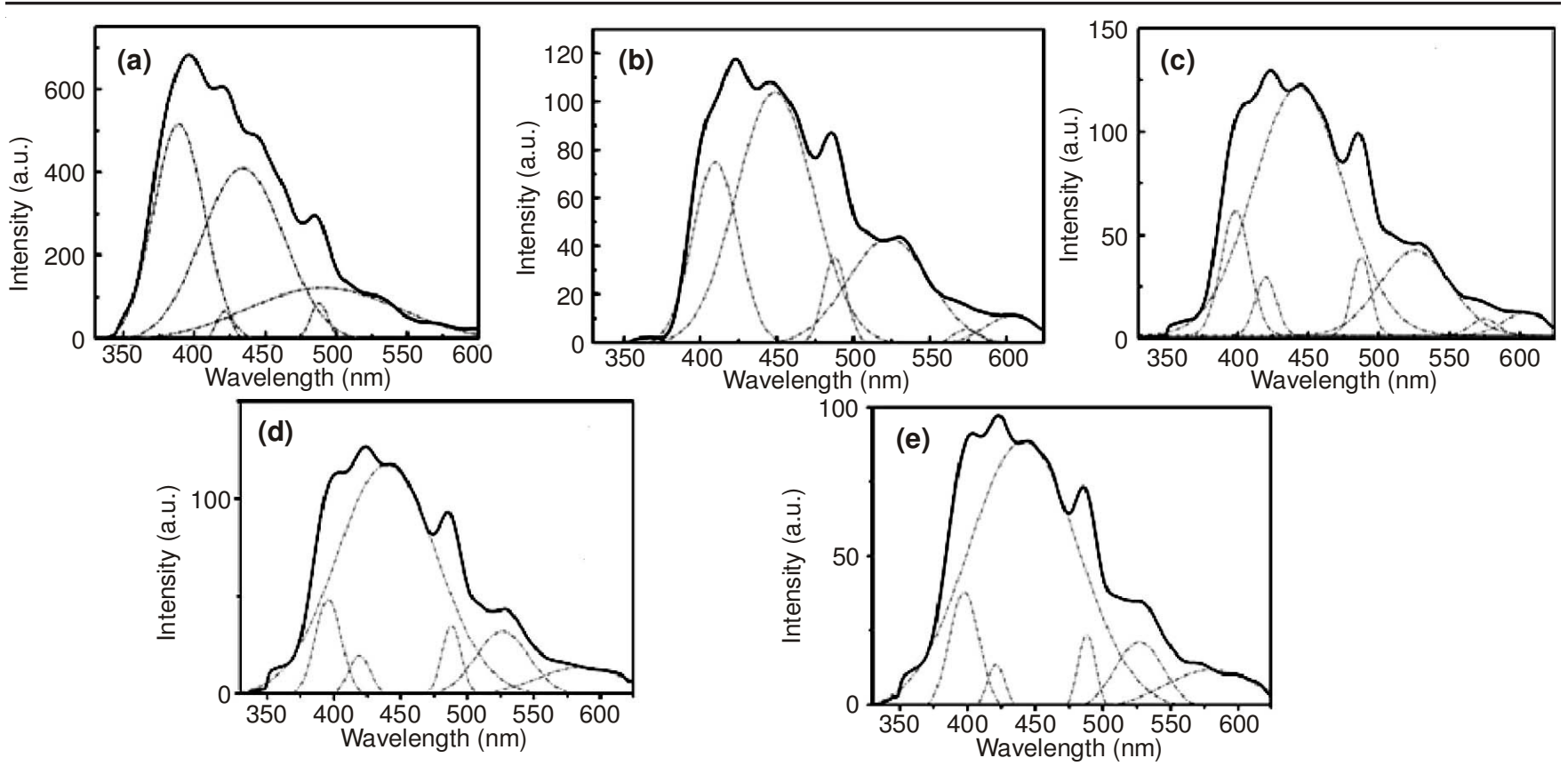

Fig. 4. Gaussian deconvolution of photoluminescence spectra of: (a) nano structure $\mathrm{ZnO}$, (b) nano structure of $\mathrm{ZnO}$ at $3 \%$ of indium proportion, (c) nano-films of $\mathrm{ZnO}$ at $5 \%$ of indium proportion, (d) nano-films of $\mathrm{ZnO}$ at $8 \%$ of indium proportion and (e) nano-films of $\mathrm{ZnO}$ at $10 \%$ of indium proportion. The main considerations in Gaussian deconvolution are: the peaks are relatively fixed; all peaks are considered; relatively high correlation coefficient $\left(r^{2}>0.99\right)$

According to reference ${ }^{22}$ and by the equation:

$$
\mathrm{E}=\mathrm{h} \times \mathrm{v}=\mathrm{h} \times \frac{\mathrm{c}}{\lambda}
$$

we calculated and drew the band-gap energy of $\mathrm{ZnO}$ nanofilms and defects such as oxygen vacancy $\left(\mathrm{V}_{\mathrm{O}}\right)$, zinc vacancy $\left(\mathrm{V}_{\mathrm{Zn}}\right)$, interstitial zinc and interstitial oxygen and new energy levels(NV) introduced by indium doping showed as Fig. 5.

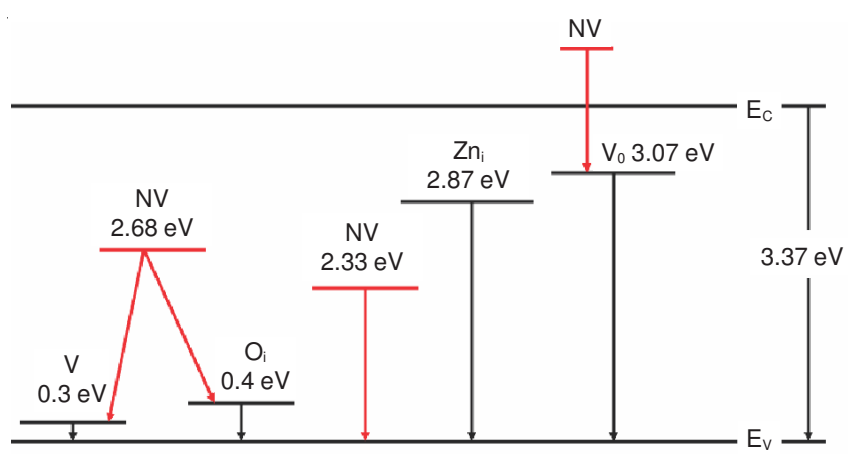

Fig. 5. Energy levels of indium-doped $\mathrm{ZnO}$ nano-films

From calculation, the nano-films band gap energy is 3.14 $\mathrm{eV}$, less than the general one of $3.37 \mathrm{eV}$, caused by poor crystalline quality. The ultraviolet emission peak of $\mathrm{ZnO}$ and indium-doped $\mathrm{ZnO}$ nano-films at 396 and $404 \mathrm{~nm}$ are caused by the transition of electrons from conduction band to valence band and transition to $\mathrm{V}_{\mathrm{O}}$ level respectively. The red shift of the UV-emission peak from $\mathrm{ZnO}$ and indium-doped $\mathrm{ZnO}$ nanofilms is the result of the increase of $V_{O}$ level that covers up the character emission peak of $\mathrm{ZnO}$ and the indium doping made lattice constant bigger than nano $\mathrm{ZnO}$ resulting a less band gap energy. There are three emission peaks of 423, 445 and $486 \mathrm{~nm}$ in the blue region of all the spectra are the results of transition from conduction band to $\mathrm{V}_{\mathrm{Zn}}$, from $\mathrm{V}_{\mathrm{O}}$ to $\mathrm{V}_{\mathrm{Zn}}$ and from $\mathrm{Zn}_{\mathrm{i}}$ to $\mathrm{V}_{\mathrm{Zn}}$ respectively according to the calculation. There is a blue shift of the green region (changing from 535-534, 532, 531 and $529 \mathrm{~nm}$ that from $\mathrm{ZnO}$ to indium-doped $\mathrm{ZnO}$ of the indium proportion 3, 5, 8 and $10 \%$, respectively) and increased intensity showed in Fig. 4 and the green emission is ascribed to the transitions from deep level to the $\mathrm{V}_{\mathrm{O}}$ level, so by calculation the blue shift can be explained that the increase and the different surrounding of the oxygen vacancies and the transitions of the three possible new energy levels caused by incorporation of indium ionics into the wurtzite structure of $\mathrm{ZnO}$ and the new energy levels moves to higher energy level with the increase of indium doping.

So that the result of indium-doped $\mathrm{ZnO}$ nano-films is that the emission peaks shift to the middle wavelength from UV and green region.

\section{Conclusion}

$\mathrm{ZnO}$ and indium-doped $\mathrm{ZnO}$ nano-films are prepared by a new two-step method on the quartz glass substrates. The zinc acetate solution is ultrasonic sprayed on the substrates at $300{ }^{\circ} \mathrm{C}$ to prepared $\mathrm{ZnO}$ seed layers. The growth orientation of $\mathrm{ZnO}$ nano films chenges from along c-axis to (101) plane with the increase of indium proportion. $\mathrm{ZnO}$ nano rods films are prepared by the method. The structure changes from prismlike nano rods to nanofilms due to the different indium proportion indicating that the dopant distorts the wurtzite structure of $\mathrm{ZnO}$ because of the different ionic radius. New energy levels are introduce into $\mathrm{ZnO}$. The increase of indium doping causes a blue shift in the green emission region and the increase and change of chemical surroundings around oxygen vacancies result a better blue emission at $404 \mathrm{~nm}$. 


\section{ACKNOWLEDGEMENTS}

The authors thank for the support of the National Natural Science Foundation of China (Grant No. 61106059, 61172028), the Encouragement Foundation for Excellent Middle-aged and Young Scientist of Shandong Province (Grant No. BS2011NJ003), the Science-Technology Program of Higher Education Institutions of Shandong Province (Grant No. J11LA10), the Doctoral Foundation of University of Jinan (Grant No. XBS0845), Shandong Foundation for Development of Science and Technology (Grant No. 2009GG20003028, 2010GG0020423).

\section{REFERENCES}

1. J. Sun, Q. Feng, J. Bian, D. Yu, M. Li, C. Li, H. Liang, J. Zhao, H. Qiu and G. Du, J. Lumin., 131, 825 (2011).

2. R. Ferro, J.A. Rodríguez and P. Bertrand, Thin Solid Films, 516, 2225 (2008)

3. Y.J. Lee, D.S. Ruby, D.W. Peters, B.B. Mckenzie and J.W.P. Hsu, Nano Lett., 8, 1501 (2008)

4. T. Szabo, J. Nemeth and I. Dekany, Colloids Surf. A, 230, 23 (2003).

5. M. Krunks, A. Katerski, T. Dedova, I. Oja Acik and A. Mere, Sol. Energy Mater. Sol. Cells, 92, 1016 (2008).

6. D.T. Phan and G.S. Chung, Appl. Surf. Sci., 257, 3285 (2011).
7. A. Marzouki, A. Lusson, F. Jomard, A. Sayari, P. Galtier, M. Oueslati and V. Sallet, J. Cryst. Growth, 312, 3063 (2010).

8. J.H. Zheng, Q. Jiang and J.S. Lian, Appl. Surf. Sci., 257, 5083 (2011).

9. G. He and K. Wang, Appl. Surf. Sci., 257, 6590 (2011).

10. S. Kerli, U. Alver, H. Yaykasli, B. Avar, A. Tanriverdi and C. Kursun, Asian J. Chem., 25, 7539 (2013).

11. X. Bie, J. Lu, Y. Wang, L. Gong, Q. Ma and Z. Ye, Appl. Surf. Sci., 257, 6125 (2011).

12. Q. Wang, G. Wang, B. Xu, J. Jie, X. Han, G. Li, Q. Li and J.G. Hou, Mater. Lett., 59, 1378 (2005).

13. W. Zhaoyang, S. Liyuan and H. Lizhong, Vacuum, 85, 397 (2010).

14. S.C. Su, Y.M. Lu, Z.Z. Zhang, C.X. Shan, B. Yao, B.H. Li, D.Z. Shen, J.Y. Zhang, D.X. Zhao and X.W. Fan, Appl. Surf. Sci., 254, 7303 (2008).

15. P. Nunes, E. Fortunato, P. Tonello, F. Braz Fernandes, P. Vilarinho and R. Martins, Vacuum, 64, 281 (2002).

16. W.S. Shi, B. Cheng, L. Zhang and E.T. Samulski, J. Appl. Phys., 98, 083502 (2005).

17. D.C. Look, J.W. Hemsky and J. Sizelove, Phys. Rev. Lett., 82, 2552 (1999).

18. M.K. Lee and H.F. Tu, J. Appl. Phys., 101, 12603 (2007).

19. W. Cheng, P. Wu, X. Zou and T. Xiao, J. Appl. Phys., 100, 054311 (2006).

20. C.-H. Tsai, W.-C. Wang, F.-L. Jenq, C.-C. Liu, C.-I. Hung and M.-P. Houng, J. Appl. Phys., 104, 053521 (2008).

21. S.A. Studenikin, N. Golego and M. Cocivera, J. Appl. Phys., 84, 2287 (1998).

22. P.S. Xu, Y. Sun, C. Sun and F.Q. Xu, Sci. China (Series A), 31, 358 (2001). 